Check for updates

Cite this: RSC Adv., 2018, 8, 111

Received 17th October 2017

Accepted 13th December 2017

DOI: 10.1039/c7ra11459a

rsc.li/rsc-advances

\section{Preparation of functionalized zirconium phosphate and its effect on the flame retardancy of silicone rubber $\dagger$}

\begin{abstract}
Yajun Zhang, Xingrong Zeng, (D) * Xuejun Lai* and Hongqiang Li (D)
How to effectively enhance the flame retardancy of silicone rubber is an important but challenging task. In this contribution, functionalized zirconium phosphate (F-ZrP) was prepared by the intercalation of 1,2,2,6,6pentamethyl-4-(vinyldiethoxysiloxy) piperidine (PMVP) into $\alpha$-zirconium phosphate ( $\alpha$-ZrP), and was employed to enhance the flame retardancy of addition-cured liquid silicone rubber (ALSR). Results showed that ALSR had no rating in the UL-94 test with the LOI value of $28.0 \%$. F-ZrP could significantly improve the flame retardancy of ALSR. When only 4.0 phr F-ZrP was added, the limiting oxygen index (LOI) value reached $31.0 \%$ and the vertical burning test (UL-94) passed the $V-0$ rating. Moreover, compared to ALSR, the peak heat release rate (PHRR) and the total heat release (THR) of ALSR/F-ZrP decreased by $54.2 \%$ and $47.5 \%$, respectively. The probable flame retardant mechanism of F-ZrP was mainly attributed to the synergism of the catalyzing carbonization and free-radical quenching effects. On the one hand, PMVP suppressed the thermal degradation of silicone chains in the condensed phase and quenched the active free-radicals in the gas phase by generating nitroxyl radicals. On the other hand, ZrP promoted silicone chain self-crosslinking and the formation of the graphitized carbons, resulting in the formation of the compact and thermostable ceramic layer, which was good barrier to protect the underlying matrix and inhibit the exchange of degradation products and oxygen.
\end{abstract}

\section{Introduction}

Silicone rubber (SR) is one of the most important highperformance polymers due to its hydrophobicity, chemical resistance, high temperature resistance and excellent electrical properties. ${ }^{1,2}$ However, the flammability of SR severely limits its further application in many fields that require flame retardancy, such as aerospace, nuclear power and electric transmission. ${ }^{\mathbf{3 , 4}}$ Among the halogen-free flame retardants for SR, metal hydroxides are the most widely used because they are cheap and environmentally-friendly. ${ }^{5}$ Unfortunately, the flame retardancy efficiency of metal hydroxides is very low and a large usage amount ( $>50 \mathrm{wt} \%)$ is necessary to make SR achieve desirable flame retardancy. In this case, the mechanical properties of SR are inevitably seriously damaged. Therefore, it is imperative to develop a more efficient flame retardant to enhance the flame retardancy of SR.

Layered nanomaterials have attracted much attention as a new generation of flame retardants, because they can endow

College of Materials Science and Engineering, South China University of Technology, No 381, Wushan Road, Tianhe District, Guangzhou 510640, China. E-mail: psxrzeng@gmail.com; msxjlai@scut.edu.cn; Fax: +86-20-87114248; Tel: +86-2087114248; +86-20-22236629

$\dagger$ Electronic supplementary information (ESI) available. See DOI: 10.1039/c7ra11459a polymers with excellent mechanical, thermal, barrier properties and flame retardancy by a small amount. ${ }^{6-8}$ For SR/layered nanocomposites, most studies were focused on the layered silicates (like montmorillonite) and layered double hydroxides. ${ }^{9-11}$ In fact, $\alpha$-zirconium phosphate is also a typical layered nanomaterial which consists of zirconium atoms in a plane and phosphate groups bonded to a different $\mathrm{Zr}$ atom above and below the plane. ${ }^{12} \alpha$-Zirconium phosphate $(\alpha-\mathrm{ZrP})$ exhibits some advantages over montmorillonite, including higher purity and ease of intercalation and/or exfoliation. ${ }^{\mathbf{1 3 , 1 4}}$ Moreover, benefiting from its elemental composition, $\alpha$-ZrP also shows the characteristic of the solid acid catalyst, ${ }^{15,16}$ which can catalyze the dehydrogenation of polymers and promote the charring of polymers. ${ }^{17}$ These characteristics suggest that $\alpha$-ZrP has the great potential in the application of the flame retardant SR. However, it is a great challenge to make zirconium phosphate dispersed uniformly in SR, because $\alpha$-ZrP is commonly organically modified by an ammonium salt bearing long alkyl chains ${ }^{\mathbf{1 8}}$ which has poor compatibility with SR, thus it is not conducive for the polysiloxane molecules to further intercalate into $\alpha$-ZrP.

Hindered amine is a family member of piperidine derivatives and it has been used as a UV stabilizer for a long time. Recently, many studies show hindered amine possesses excellent flame retardancy, because it degrades thermally to generate efficient and regenerable free radical scavengers which interrupt and suppress the free radical combustion progress of polymers. ${ }^{19,20}$ 
Moreover, hindered amine has the structure of tertiary amine in the heterocyclic ring, suggesting it can act as a surfactant for $\alpha$ ZrP. Thus, if $\alpha$-ZrP is functionalized with hindered amine, there would be a strong possibility to greatly improve the flame retardancy of SR.

In this work, in order to enhance the compatibility between ZrP and SR, a novel hindered amine containing silane and carbon carbon double bond, 1,2,2,6,6-pentamethyl-4(vinyldiethoxysiloxy)-piperidine (PMVP) was synthesized through the transesterification of vinyltriethoxysilane with 1,2,2,6,6-pentamethyl-4-piperidinol (PMPO). Then PMVP was employed to prepare the functionalized zirconium phosphate (F-ZrP) via the intercalation reaction. The structure and morphology of F-ZrP were characterized by Fourier transform infrared spectroscopy (FTIR), X-ray diffraction (XRD) and transmission electron microscopy (TEM). F-ZrP was used to flame-retard addition-cure liquid silicone rubber (ALSR). The flame-retardant properties of ALSR/F-ZrP nanocomposite were systematically studied by the limiting oxygen index (LOI), UL-94 and cone calorimetry measurements. This investigation would develop a new and efficient strategy to prepare the highperformance silicone rubber.

\section{Experimental}

\subsection{Materials}

$\alpha$-ZrP was synthesized according to Sun et al. ${ }^{21}$ vinyltriethoxysilane (VTES) was provided by Qufu Chenguang Chemical Co., Ltd., China. 1,2,2,6,6-Pentamethyl-4-piperidinol
(PMPO) was supplied by Energy Chemical Co., Ltd., China. Tetrabutyl titanate (TBT) was purchased from Tianjin Fuchen Chemical Reagent Factory, China. Vinyl-terminated poly (dimethylsiloxane) (VPDMS, viscosity was $20000 \mathrm{mPa} s$ and vinyl content was $0.12 \mathrm{wt} \%$ ), ploy(hydromethylsiloxane) (PHMS, viscosity was $160 \mathrm{mPa} \mathrm{s}$ and hydride content was $0.70 \mathrm{wt} \%$ ), platinum(0)-1,3-divinyl-1,1,3,3-tetramethydisiloxane complex (Karstedt's catalyst, $3000 \mathrm{ppm}$ ) and 1-ethynylcyclohexanol were supplied by Guangzhou Tinci Silicon Technology Co., Ltd., China. Fumed silica (M-5) was purchased from Cabot Co., Ltd., USA.

\subsection{Preparation of functionalized zirconium phosphate}

PMVP was prepared as illustrated in Fig. 1a. In a $500 \mathrm{~mL}$ fourneck flask, $19.0 \mathrm{~g}$ VTES $(0.1 \mathrm{~mol})$ was added to a solution composed of $0.2 \mathrm{~g}$ TBT and $200 \mathrm{~mL}$ toluene with stirring. The reaction system was heated to $70{ }^{\circ} \mathrm{C}$, and $17.1 \mathrm{~g}$ PMPO $(0.1 \mathrm{~mol})$ was added dropwise with vigorous stirring. Afterwards, the reaction was kept at $70{ }^{\circ} \mathrm{C}$ for $2 \mathrm{~h}$. Then, the reaction was maintained for another $2 \mathrm{~h}$ under the reduced pressure and the toluene was removed to obtain PMVP. The chemical structure of PMVP was determined by ${ }^{1} \mathrm{H}$ NMR $\left(300 \mathrm{MHz} \mathrm{CDCl}_{3}, \delta\right): 1.1-$ $1.3\left(\mathrm{C}-\mathrm{CH}_{3}, 18 \mathrm{H}\right), \quad 1.50-1.83\left(\mathrm{C}-\mathrm{CH}_{2}, 4 \mathrm{H}\right), \quad 2.24\left(\mathrm{~N}-\mathrm{CH}_{3}, 3 \mathrm{H}\right)$, 2.35(O-CH-, $1 \mathrm{H}), 3.83\left(\mathrm{O}-\mathrm{CH}_{2}-, 4 \mathrm{H}\right), 5.87-6.15\left(-\mathrm{CH}=\mathrm{CH}_{2}, 3 \mathrm{H}\right)$. $2.8 \mathrm{~g} \alpha$-ZrP $(0.01 \mathrm{~mol})$ was placed in a three-neck flask and dispersed by $280 \mathrm{~mL}$ toluene, then $6.3 \mathrm{~g}$ PMVP $(0.02 \mathrm{~mol})$ was added dropwise into the suspension followed by $10 \mathrm{~min}$ of ultrasonication. The mixture was stirred for another $7 \mathrm{~h}$ at $30{ }^{\circ} \mathrm{C}$. Finally, the product was washed three times with toluene

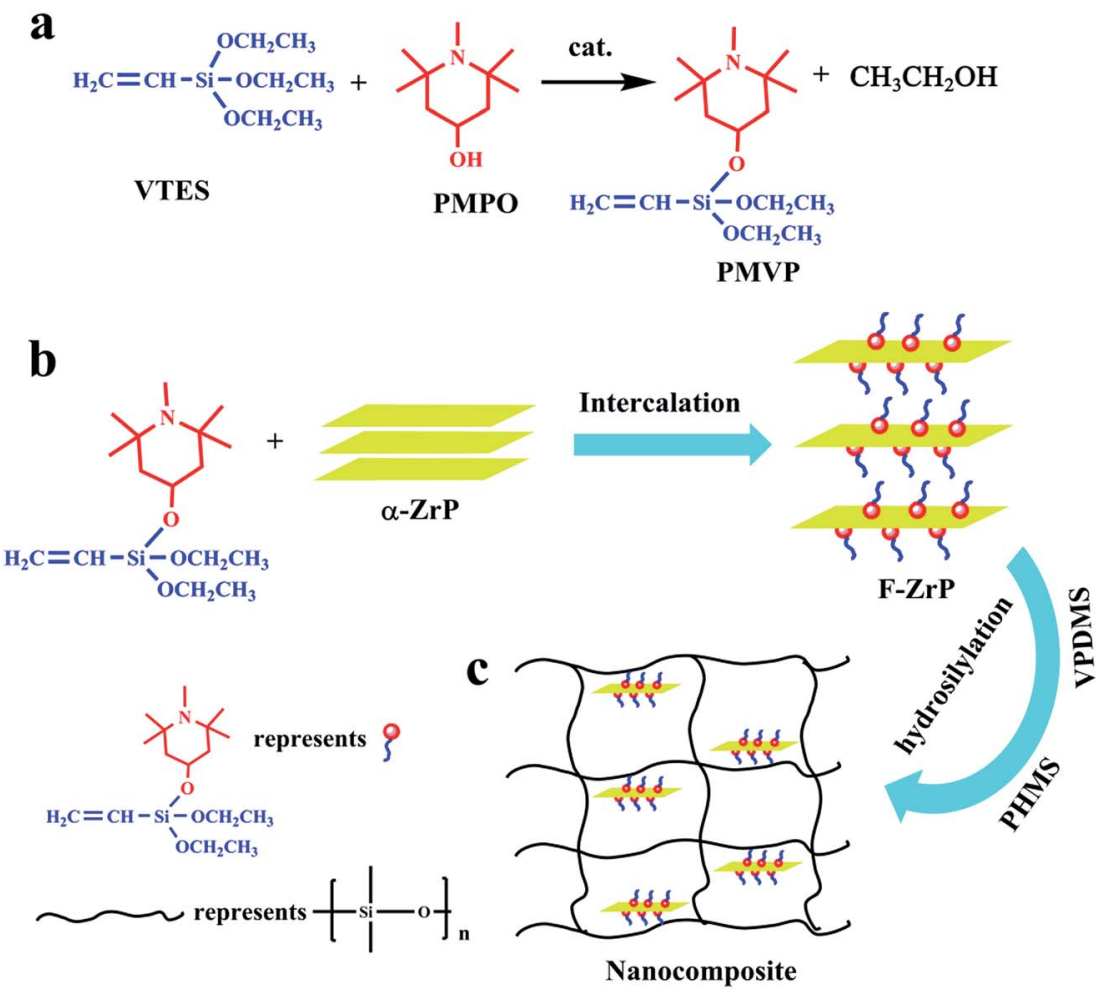

Fig. 1 Schematic illustration for the preparation routes: (a) PMPV, (b) F-ZrP and (c) ALSR/F-ZrP nanocomposite. 
and ethanol respectively, filtered and dried in an oven at $65{ }^{\circ} \mathrm{C}$ for $12 \mathrm{~h}$. The functionalized $\mathrm{ZrP}$ (F-ZrP) was obtained and the intercalation reaction is illustrated in Fig. 1b. The chemical formula of F-ZrP was determined by the EDS: $\mathrm{Zr}\left(\mathrm{HPO}_{4}\right)_{2}(\mathrm{PMVP})_{0.79}$.

\subsection{Preparation of the flame-retardant ALSR composites}

F-ZrP was suspended in toluene through ultrasonication for $0.5 \mathrm{~h}$. Then, $100 \mathrm{phr}$ VPDMS was added into the suspension with vigorous stirring at $30{ }^{\circ} \mathrm{C}$ for $5 \mathrm{~h}$. Afterwards, the toluene was removed from the VPDMS/F-ZrP mixture. Subsequently, 40 phr fume silica, 1.5 phr PHMS, 0.5 phr Karstedt's catalyst and $0.06 \mathrm{phr}$ 1-ethynylcyclohexanol were mixed uniformly with the VPDMS/F-ZrP mixture by a kneader reactor (SH-5, RuGao ShengTeng Kneading Machinery Manufacturing Co., Ltd., China). Finally, the mixture was vulcanized at $120^{\circ} \mathrm{C}$ for $10 \mathrm{~min}$ under $8 \mathrm{MPa}$ by a press vulcanizer $($ XQLB-350 $\times 350$, Shanghai Rubber Machinery Works No. 1 Co., Ltd., China) to obtain ALSR/F-ZrP nanocomposite. For comparision, ALSR samples with $4 \mathrm{phr} \alpha$-ZrP and $4 \mathrm{phr}$ PMVP were also obtained by the same method, denoted as ALSR/ $\alpha-Z r P$ and ALSR/PMVP. The preparation of ALSR/F-ZrP nanocomposite is illustrated in Fig. 1c and the formulas of ALSR and its composites are presented in Table 1.

\subsection{Characterization}

2.4.1 Fourier transform infrared spectrometry (FTIR). The FTIR spectra of samples were obtained using the Bruker Tensor 27 spectrometer over the wave number range of $400-4000 \mathrm{~cm}^{-1}$. The scan number was 16 times and the resolution was $4 \mathrm{~cm}^{-1}$.

2.4.2 ${ }^{1} \mathrm{H}$ nuclear magnetic resonance spectrometry $\left({ }^{1} \mathrm{H}\right.$ NMR). The ${ }^{1} \mathrm{H}$ NMR spectra were obtained by using a Bruker AV 300 NMR spectrometer with $\mathrm{CDCl}_{3}$ as a solvent and tetramethylsilane as the internal standard.

2.4.3 Transmission electron microscopy (TEM). The morphology and structure of F-ZrP and its nanocomposite were studied by transmission electron microscopy (TEM) (JEM$2100 \mathrm{~F}$, Japan) with an acceleration voltage of $100 \mathrm{kV}$. The nanocomposite was cryomicrotomed with a diamond knife into a thickness of 50-70 $\mathrm{nm}$. The ultrathin films were placed on copper grids before observation. $\alpha$-ZrP and F-ZrP were dispersed

Table 1 The formulas of ALSR and its composites

\begin{tabular}{lllll}
\hline Sample & VPDMS $^{a}(\mathrm{phr})$ & $\alpha$-ZrP (phr) & PMVP (phr) & F-ZrP (phr) \\
\hline ALSR & 100 & 0 & 0 & 0 \\
ALSR/ $\alpha$-ZrP & 100 & 4.0 & 0 & 0 \\
ALSR/PMVP & 100 & 0 & 4.0 & 0 \\
ALSR/F-ZrP-1 & 100 & 0 & 0 & 1 \\
ALSR/F-ZrP-2 & 100 & 0 & 0 & 2 \\
ALSR/F-ZrP-3 & 100 & 0 & 0 & 3 \\
ALSR/F-ZrP-4 & 100 & 0 & 0 & 4
\end{tabular}

\footnotetext{
${ }^{a}$ The other ingredients of ALSR samples were fixed as: $40 \mathrm{phr}$ (parts per 100 parts of VPDMS) of silica, 1.5 phr PHMS, 0.5 phr Karstedt's catalyst and $0.06 \mathrm{phr}$ 1-ethynylcyclohexanol.
}

in the ethanol with $0.5 \mathrm{mg} \mathrm{mL}^{-1}$ by ultrasonication and then dripped onto copper grids.

2.4.4 X-ray diffraction (XRD). The crystalline structure was analyzed by XRD (X'Pert $\mathrm{PRO}$, Holland) with $\mathrm{Cu}-\mathrm{K} \alpha$ radiation source $(\lambda=0.154 \mathrm{~nm})$ in the range of $2 \theta=1-60^{\circ}$ using the step length of $0.05^{\circ}$. The interlayer distance of $\alpha-\mathrm{ZrP}$ and F-ZrP was calculated using Bragg's law: $2 d \sin \theta=n \lambda$, where $d$ was the crystalline interplanar spacing, $\theta$ was the angle between the incident X-ray and the corresponding crystal surface, $\lambda$ was the wavelength of X-ray and $n$ was the diffraction series.

2.4.5 Thermogravimetric analysis (TGA). The thermogravimetric analysis was carried out by using a thermogravimeter (TG209, Netzsch Instruments Co., Germany) from $30{ }^{\circ} \mathrm{C}$ to $900{ }^{\circ} \mathrm{C}$ at a linear heating rate of $20{ }^{\circ} \mathrm{C} \mathrm{min}{ }^{-1}$ under air atmosphere (experimental error: $\pm 0.1 \mathrm{wt} \%$ ). The sample's heatresistance index was calculated by eqn 1

$$
T_{\text {heat-resistance index }}=0.49 \times\left[T_{5 \%}+0.6 \times\left(T_{30 \%}-T_{5 \%}\right)\right]
$$

Where $T_{5 \%}$ and $T_{30 \%}$ were corresponding decomposition temperature of $5 \%$ and $30 \%$ weight loss, respectively. ${ }^{22}$

2.4.6 Flammability test. The flame retardancy was measured by using the limiting oxygen index test (HC-2, Jiangning, China) according to ASTM D2863-08 and the vertical burning test (CZF-3, Jiangning, China) for UL-94 according to ASTM D6413-99. The dimensions of the specimens for the vertical burning test were $127 \mathrm{~mm} \times 12.7 \mathrm{~mm} \times$ $3.2 \mathrm{~mm}$. The rating of the samples was determined during the vertical burning test according to Table $\mathrm{S} 1 \dagger$ and the standard of self-extinguishing for SR was based on whether or not afterflame or afterglow of any specimen spread up to the holding clamp.

2.4.7 Mechanical test. The tensile and tear tests of the cured samples were conducted on a universal testing machine (UT-1080, China) according to the ISO 37: 2005 and ISO 34-1: 2004, respectively.

2.4.8 Cone calorimeter test (CCT). The cone calorimeter test was carried out by using a cone calorimeter (Fire Testing Technology Co., UK) according to ISO 5660. Each specimen, with the dimensions of $100 \mathrm{~mm} \times 100 \mathrm{~mm} \times 4.0 \mathrm{~mm}$, was wrapped in aluminium foil and exposed horizontally to an external heat flux of $35 \mathrm{~kW} \mathrm{~m}^{-2}$. The parameters measured were time to ignition $\left(t_{\text {ign }}, \mathrm{s}\right)$, Total Heat Release (THR, $\mathrm{MJ} \mathrm{m}^{-2}$ ), Heat Release Rate (HRR, $\mathrm{kW} \mathrm{m}^{-2}$ ), the relative peak (PHRR, $\mathrm{kW} \mathrm{m}^{-2}$ ) and Time To PHRR $\left(t_{\mathrm{PHRR}}\right)$. All samples were run in duplicate and the average value is reported. The residue of flame retardant ALSR after the cone calorimeter test was photographed by a digital camera (ILCE 5100L, Sony Inc., Japan).

2.4.9 Scanning electron microscopy (SEM). The morphology of the char residue was observed by SEM (EVO18, Carl Zeiss Jena, Co, Germany) with an accelerating voltage of 10.0-20.0 kV. The white ash on the surface of the residue was removed with the brush and subsequently was sputter-coated with a conductive gold layer before observation.

2.4.10 Thermogravimetry-Fourier transform infrared spectrometry (TG-FTIR). The TG-IR instrument consists of a thermogravimeter (TG209, Netzsch Instruments Co., Germany), 
a Fourier transform infrared spectrometer (Tensor 27, Bruker Optics Inc., Germany), and a transfer tube with an inner diameter of $1 \mathrm{~mm}$ connected the TG and the infrared cell. The investigation was carried out from $30{ }^{\circ} \mathrm{C}$ to $900{ }^{\circ} \mathrm{C}$ at a linear heating rate of $20^{\circ} \mathrm{C} \mathrm{min}^{-1}$.

2.4.11 X-ray photoelectron spectroscopy (XPS). XPS spectra of the char residues were recorded on a Kratos Axis Ulra DLD Xray photoelectron spectrometer employing a monochromatic $\mathrm{Al}$ $\mathrm{K} \alpha \mathrm{X}$-ray source.

\section{Results and discussion}

\subsection{Characterization of F-ZrP}

Fig. 2a shows the XRD patterns of $\alpha$-ZrP and F-ZrP. As can be seen, the typical diffraction peaks at $2 \theta=11.6,19.8$ and $25.0^{\circ}$ correspond to the primary diffraction of (002), (110) and (112) planes of $\alpha$-ZrP, respectively. ${ }^{23}$ The interlayer distance of (002) plane was $0.76 \mathrm{~nm}$, which was estimated from Bragg's law. ${ }^{13}$ After $\alpha$-ZrP was functionalized by PMVP, the diffraction peak of (002) plane was shifted to a low position $\left(2 \theta=5.3^{\circ}\right)$, indicating an increase in the interlayer spacing to $1.66 \mathrm{~nm} .{ }^{24}$ The increase of the interlayer spacing was beneficial to the intercalation of silicone chains into $\alpha$-ZrP, and improved the dispersion of $\alpha$-ZrP in SR.

The FTIR spectra of $\alpha$-ZrP and F-ZrP are presented in Fig. $2 b$. For $\alpha-Z r P$, the absorption peaks at 3593 and $3510 \mathrm{~cm}^{-1}$ were attributed to the asymmetric stretching vibration of $\mathrm{O}-\mathrm{H}$ in water molecules. ${ }^{25}$ The band around $3157 \mathrm{~cm}^{-1}$ was assigned to the stretching vibration of $\mathrm{O}-\mathrm{H}$ in $\mathrm{POH}$, while the deformation peak was located at $1618 \mathrm{~cm}^{-1} .^{26}$ Compared with $\alpha$-ZrP, there were some new absorbance peaks in the spectrum of F-ZrP. The absorption peaks at 2970 and $2925 \mathrm{~cm}^{-1}$ were assigned to $-\mathrm{CH}_{3}$ and $-\mathrm{CH}_{2}$, and the absorption peak at $1680 \mathrm{~cm}^{-1}$ was from $\mathrm{C}=\mathrm{C}$ stretching vibration. The characteristic band of $\mathrm{C}-\mathrm{N}$ appeared at 1530 and $1510 \mathrm{~cm}^{-1}$, while the deformation vibration of $\mathrm{C}-\mathrm{C}$ in the methyl attached to the heterocyclic ring was observed at 1374 and $1342 \mathrm{~cm}^{-1} .^{27}$ The strong absorption band around $1033 \mathrm{~cm}^{-1}$ became broader due to the overlap of $\mathrm{P}-\mathrm{O}$ and $\mathrm{Si}-\mathrm{O}$.

In order to confirm whether the laminate structure of $\alpha$-ZrP was destroyed after functionalized by PMVP, the morphology of $\alpha$-ZrP and F-ZrP was observed by TEM. The results were shown in Fig. $2 c$ and d. As can be seen, $\alpha$-ZrP exhibited a typically smooth layered structure and packed tightly. ${ }^{28}$ After ZrP was functionalized by PMVP, the particle shape was not affected and was nearly identical to that of $\alpha$-ZrP. Combining FTIR, XRD and TEM results, it revealed that PMVP was successfully intercalated into $\alpha$-ZrP.

\subsection{Morphology of the ALSR/F-ZrP nanocomposite}

The homogeneous dispersion of nano flame retardants was the key factor affected its flame-retardant efficiency, ${ }^{29}$ thus it is necessary to study the dispersion of F-ZrP in ALSR. Fig. 3 shows the XRD patterns and TEM images of ALSR/ $\alpha-Z r P$ and ALSR/FZrP-4. As seen from Fig. 3, for ALSR/ $\alpha$-ZrP composite, the main characteristic peak of $\alpha-\mathrm{ZrP}$ remained at $11.6^{\circ}$, indicating that $\alpha$-ZrP still existed with a structure of stack in ALSR. However, the characteristic peak of $\alpha$-ZrP disappeared in the XRD pattern of ALSR/F-ZrP-4, revealing that F-ZrP nanosheets were well exfoliated in ALSR.

The TEM images further confirmed the dispersion of $\alpha$-ZrP and F-ZrP in ALSR. As can be seen, $\alpha$-ZrP aggregated very
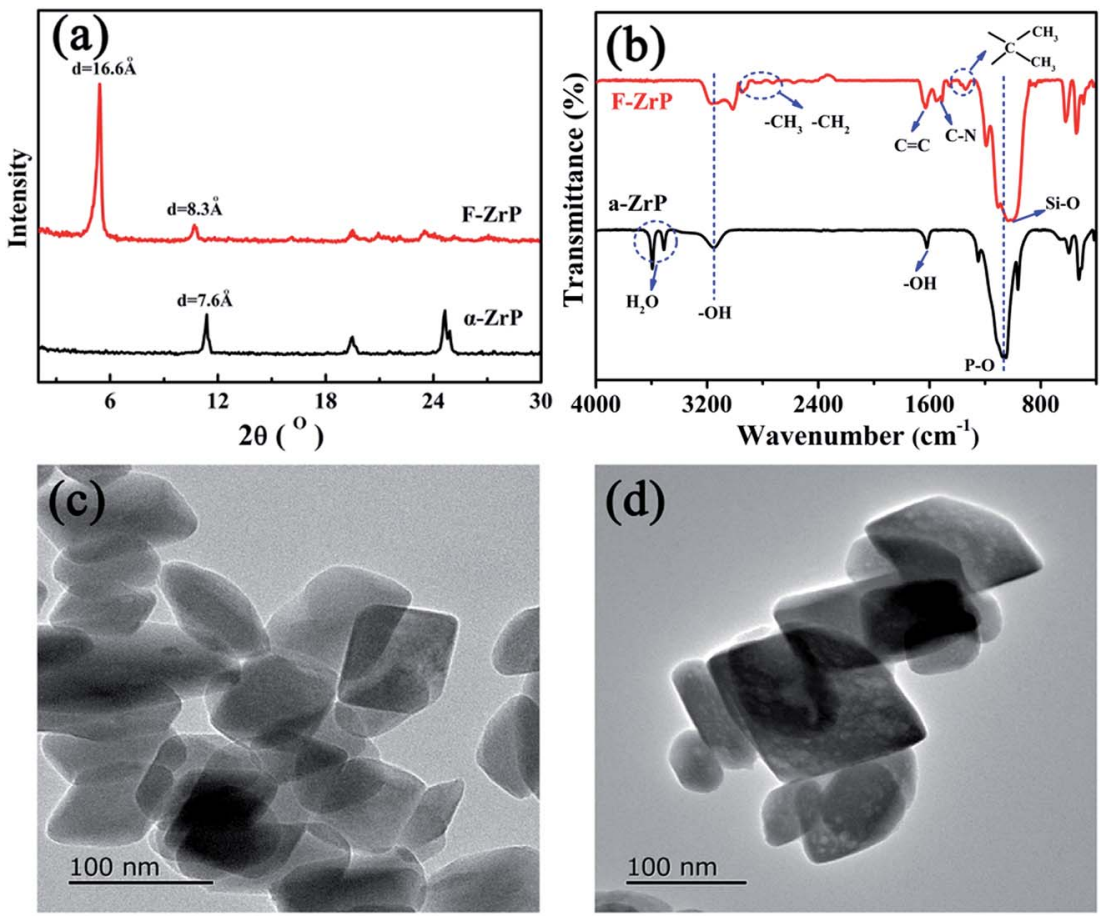

Fig. 2 XRD patterns (a) and FTIR spectra (b) of $\alpha$-ZrP and F-ZrP, and TEM images of $\alpha$-ZrP (c) and F-ZrP (d). 


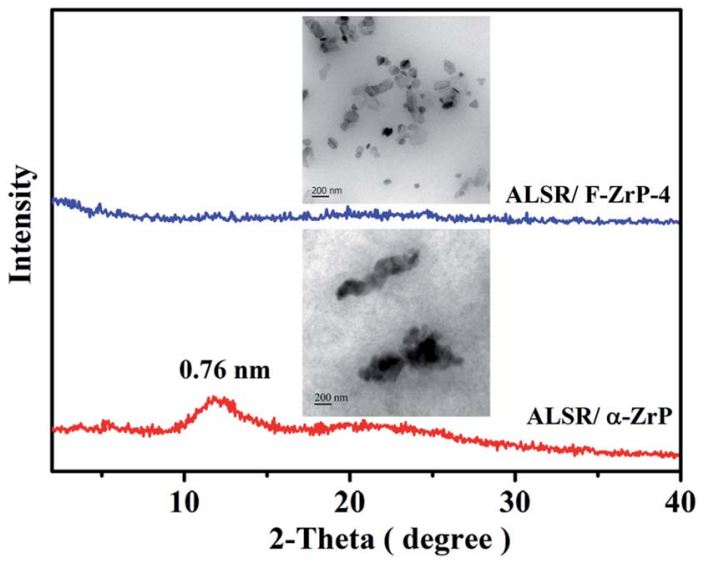

Fig. 3 XRD patterns and TEM images of ALSR/ $\alpha-Z r P$ and ALSR/FZrP-4.

seriously and dispersed poorly in ALSR due to the strong polarity. F-ZrP presented thin flakes and dispersed well in the matrix. PMVP had the silane structure and vinyl group, of which silane structure enhanced the compatibility between F-ZrP and silicone rubber, and vinyl group could link to silicone chains by the hydrosilylation reaction, which improved the interfacial interactions between F-ZrP and silicone rubber. Combining TEM and XRD results, it can be concluded that F-ZrP was exfoliated to thin flaked and dispersed well in ALSR.

\subsection{Thermal stability of ALSR and its composites}

The TGA curves of ALSR, ALSR/PMVP, ALSR/ $\alpha$-ZrP and ALSR/FZrP-4 are presented in Fig. 4, and the corresponding characteristic data are summarized in Table 2 . As can be seen, $T_{5 \%}$ and $T_{\text {heat-resistance index }}$ of ALSR $/ \alpha$-ZrP were almost the same to those of ALSR, but the residue at $800{ }^{\circ} \mathrm{C}$ increased from $43.3 \mathrm{wt} \%$ to $46.4 \mathrm{wt} \%$ due to the catalyzing carbonization effect of $\mathrm{ZrP}$ itself. ${ }^{15}$ Compared with ALSR, the $T_{5 \%}$ of ALSR/PMVP decreased from $394{ }^{\circ} \mathrm{C}$ to $386{ }^{\circ} \mathrm{C}$ due to the poor thermoxidation stability

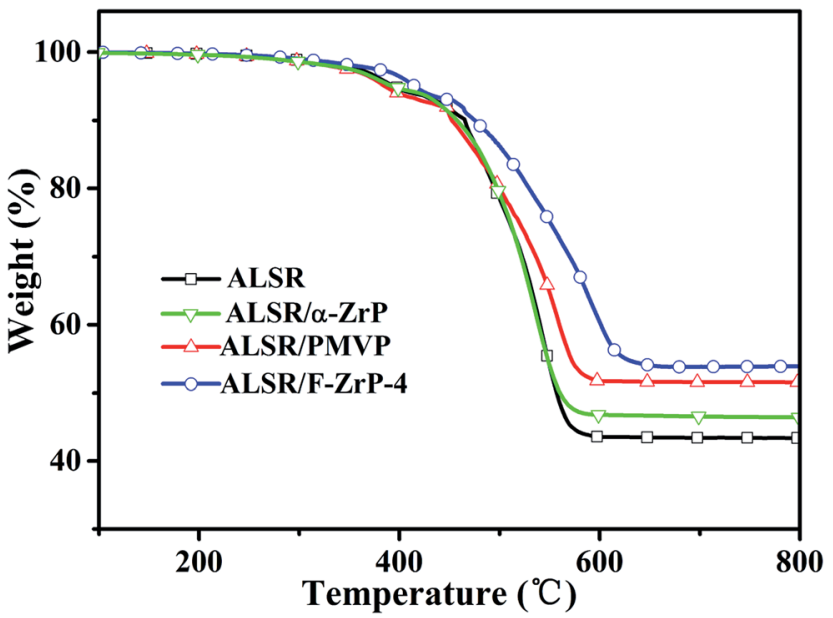

Fig. 4 TGA curves of ALSR, ALSR/PMVP, ALSR/ $\alpha-Z r P$ and ALSR/FZrP-4.
Table 2 Characteristic data obtained from TG curves

\begin{tabular}{|c|c|c|c|c|}
\hline Sample & $\begin{array}{l}T_{5 \%} \\
\left({ }^{\circ} \mathrm{C}\right)\end{array}$ & $\begin{array}{l}T_{30 \%} \\
\left({ }^{\circ} \mathrm{C}\right)\end{array}$ & $\begin{array}{l}T_{\text {heat-resistance index* }} \\
\left({ }^{\circ} \mathrm{C}\right)\end{array}$ & $\begin{array}{l}\text { Residue } \\
\text { at } 800^{\circ} \mathrm{C}(\mathrm{wt} \%)\end{array}$ \\
\hline ALSR & 394 & 522 & 231 & 43.3 \\
\hline $\mathrm{ALSR} / \alpha-\mathrm{ZrP}$ & 392 & 521 & 230 & 46.4 \\
\hline ALSR/PMVP & 386 & 536 & 233 & 51.4 \\
\hline ALSR/F-ZrP-4 & 415 & 570 & 249 & 53.8 \\
\hline
\end{tabular}

of PMVP. However, the $T_{\text {heat-resistance index }}$ of ALSR/PMVP increased from $231{ }^{\circ} \mathrm{C}$ to $233{ }^{\circ} \mathrm{C}$ and the residue at $800{ }^{\circ} \mathrm{C}$ increased from $43.3 \mathrm{wt} \%$ to $51.4 \mathrm{wt} \%$. The reason might be that in the air, PMVP was oxidized easily to generate the efficient and regenerable free-radical scavengers - nitroxyl radicals, ${ }^{19}$ which could restrain the free-radical chemical reactions during the thermal degradation of ALSR. For ALSR/F-ZrP-4, the $T_{5 \%}$ increased by $21^{\circ} \mathrm{C}$ compared with ALSR, due to the barrier effect of ZrP nanoplatelets, which delayed the oxidative degradation of silicone chains and PMVP. Moreover, $T_{\text {heat-resistance index }}$ and the residue at $800{ }^{\circ} \mathrm{C}$ also significantly increased. The results revealed that $\mathrm{F}-\mathrm{ZrP}$ could greatly improve the thermal stability of ALSR, which was attributed to the synergism of PMVP and nano ZrP.

\subsection{The flame retardancy and mechanical properties of ALSR and its composites}

Table 3 shows the flame retardancy of ALSR and its composites. As can be seen, ALSR had no rating in the UL-94 test with the LOI value of $28.0 \%$. When incorporating $4.0 \mathrm{phr}$ of $\alpha-\mathrm{ZrP}$ or PMVP, the LOI of the composites increased to $28.3 \%$ and $28.9 \%$ respectively, but they still classed no rating in the UL-94 test. However, F-ZrP could significantly improve the flame retardancy of ALSR. When the F-ZrP content was $2 \mathrm{phr}$, the LOI value of ALSR increased to $29.5 \%$ and it was self-extinguished in the UL-94 test. When the F-ZrP content was 4 phr, the nanocomposite reached the UL-94 V-0 rating and its LOI value increased to $31.0 \%$.

Table S2 $\uparrow$ shows the mechanical properties of ALSR and its composites. As seen from Table S2, $\dagger$ compared to ALSR, the tensile strength and tear strength of ALSR/ $\alpha-Z r P$ decreased slight. When 4 phr PMVP was added, the tensile strength of ALSR increased from 7.62 $\mathrm{MPa}$ to $7.98 \mathrm{MPa}$ and the tear strength of ALSR increased from $20.6 \mathrm{kN} \mathrm{m}^{-1}$ to $23.9 \mathrm{kN} \mathrm{m}^{-1}$.

Table 3 The flame retardancy of ALSR and its composites ${ }^{a}$

\begin{tabular}{llll}
\hline Sample & LOI (\%) & UL-94 & Self-extinguishing \\
\hline ALSR & $28.0 \pm 0.1$ & NR & No \\
ALSR/ $\alpha-Z r P$ & $28.3 \pm 0.1$ & NR & No \\
ALSR/PMVP & $28.9 \pm 0.2$ & NR & Yes \\
ALSR/F-ZrP-1 & $28.5 \pm 0.1$ & NR & No \\
ALSR/F-ZrP-2 & $29.5 \pm 0.1$ & NR & Yes \\
ALSR/F-ZrP-3 & $30.0 \pm 0.2$ & V-1 & Yes \\
ALSR/F-ZrP-4 & $31.0 \pm 0.1$ & V-0 & Yes
\end{tabular}

${ }^{a}$ NR represents no rating. 
PMVP had vinyl group which could link to silicone chains by the hydrosilylation reaction, and the nitrogen atoms in PMVP can form the strong hydrogen-bonds with the hydroxyl groups on the surface of $\mathrm{SiO}_{2}$, thus PMVP enhanced the interfacial interactions between silicone chains and $\mathrm{SiO}_{2}$, resulting in the increase of mechanical properties of ALSR. F-ZrP could effectively improve the mechanical properties of ALSR. When the content of F-ZrP was $4 \mathrm{phr}$, the tensile strength of ALSR increased from 7.62 MPa to 8.35 MPa, and the tear strength of ALSR increased from $20.6 \mathrm{kN} \mathrm{m}^{-1}$ to $26.0 \mathrm{kN} \mathrm{m}^{-1}$. The reason might be attributed to the improved interfacial interactions and dispersion of $\mathrm{ZrP}$ nano platelets in ALSR.

The cone calorimeter (CC) is a useful bench-scale for testing flammability properties of materials in real fire condition. ${ }^{30} \mathrm{In}$ order to detailedly study the effect of F-ZrP on the flame retardancy of ALSR, the burning behavior of ALSR, ALSR/PMVP, ALSR/ $\alpha$-ZrP and ALSR/F-ZrP-4 was characterized by CC test. Fig. 5 shows the HRR and THR curves of ALSR, ALSR/PMVP, ALSR/ $\alpha$-ZrP and ALSR/F-ZrP-4, and some important parameters were summarized in Table 4. From Fig. 5 and Table 4, it can be observed that ALSR without additives was ignited soon $\left(t_{\mathrm{ign}}=\right.$ $16 \mathrm{~s}$ ) and burned rapidly. At $143 \mathrm{~s}$, HRR reached peak value which was $251 \mathrm{~kW} \mathrm{~m}{ }^{-2}$. When $\alpha$-ZrP was added, the $t_{\text {ign }}$ and $t_{\mathrm{PHRR}}$ of ALSR/ $\alpha$-ZrP were reduced slightly, but the PHRR decreased from $251 \mathrm{~kW} \mathrm{~m}^{-2}$ to $232 \mathrm{~kW} \mathrm{~m}^{-2}$, compared with ALSR. This was because $\alpha$-ZrP catalyzed silicone chains selfcrosslinking to form a protection layer, accompanied by $\mathrm{CH}_{4}$ and the release of $\mathrm{CH}_{4}$ led to the decrease of the $t_{\mathrm{ign}}$ and $t_{\mathrm{PHRR}}$. However, the flame retardant efficiency of ALSR/ $\alpha$-ZrP was very low due to the poor dispersion of $\alpha$-ZrP. When PMVP was individually introduced to ALSR, the $t_{\mathrm{ign}}$ and $t_{\mathrm{PHRR}}$ of ALSR/ PMVP was prolonged to $35 \mathrm{~s}$ and $159 \mathrm{~s}$, respectively. Meanwhile, the PHRR value decreased from $251 \mathrm{~kW} \mathrm{~m}^{-2}$ to $217 \mathrm{~kW} \mathrm{~m}^{-2}$ and the THR value decreased from $59 \mathrm{MJ} \mathrm{m}^{-2}$ to $40 \mathrm{MJ} \mathrm{m}{ }^{-2}$, compared with ALSR. During the combustion, PMVP degraded thermally to generate the nitroxyl radicals, which not only suppressed the degradation of ALSR in the condensed phase to reduce the generation of combustile gas, but also impeded the chain reactions of combustion in the gas phase. ${ }^{19,20}$ When F-ZrP was added, the $t_{\text {ign }}$ of ALSR/F-ZrP-4 was $42 \mathrm{~s}$, prolonged by $7 \mathrm{~s}$ compared with ALSR/PMVP and $26 \mathrm{~s}$ comapred with ALSR. The results indicated that on the one
Table 4 Some important parameters obtained from cone calorimeter tests

\begin{tabular}{lccll}
\hline Sample & $t_{\text {ign }}(\mathrm{s})$ & $t_{\text {PHRR }}(\mathrm{s})$ & PHRR $\left(\mathrm{kW} \mathrm{m}^{-2}\right)$ & THR $\left(\mathrm{MJ} \mathrm{m}^{-2}\right)$ \\
\hline ALSR & $16 \pm 5$ & $143 \pm 4$ & $251 \pm 5$ & $59 \pm 3$ \\
ALSR/ $\alpha$-ZrP & $14 \pm 3$ & $126 \pm 2$ & $232 \pm 11$ & $57 \pm 6$ \\
ALSR/PMVP & $35 \pm 4$ & $159 \pm 3$ & $217 \pm 7$ & $49 \pm 4$ \\
ALSR/F-ZrP-4 & $42 \pm 3$ & $149 \pm 5$ & $115 \pm 6$ & $31 \pm 2$
\end{tabular}

hand, ZrP nanoplatelets delayed the release of combustile gas by the barrier effect. On the other hand, PMVP in the interlayer of $\mathrm{ZrP}$ suppressed the generation of combustile gas by freeradical quenching effect. Most notably, compared with ALSR, the PHRR and THR values of ALSR/F-ZrP-4 decreased by $54.2 \%$ and $47.5 \%$, respectively due to the synergism of the catalyzing carbonization and free-radical quenching mechanism.

\subsection{Morphology analysis of the residue char}

Fig. 6 shows the digital photographs and SEM images of residual chars for ALSR and its composites after cone tests. As seen from digital photographs, the residue of ALSR without additives was fragmented, which was mainly composed of loose amorphous silica, and could not prevent the polymer underneath from oxygen and combustible gases. ${ }^{31}$ When $\alpha$-ZrP was added, the residue was intact and hard, but still bumpy and porous. After incorporating PMVP, the char layer was loose and had many holes and cracks. In contrast, the residue of ALSR/ F-ZrP-4 was integrated and compact.

As seen from SEM images in Fig. 6, the residues of ALSR and ALSR/PMVP were both tousy and porous, revealing that PMVP couldn't effectively improve the quality of the residue. When $\alpha$-ZrP was added, the residue was continuous and flat, but had some cracks, indicating $\alpha$-ZrP could improve the quality of residue layers to some extent. As for ALSR/F-ZrP-4, the microstructure of residue was not only continuous and smooth, but also very compact, which was a good barrier to protect the underlying polymer and inhibit the exchange of degradation products, combustible gases and oxygen. The remarkable enhancement of residue surface for ALSR/F-ZrP-4 might be attributed to two aspects. On the one hand, PMVP suppressed the degradation of ALSR by free-radical quenching effect to
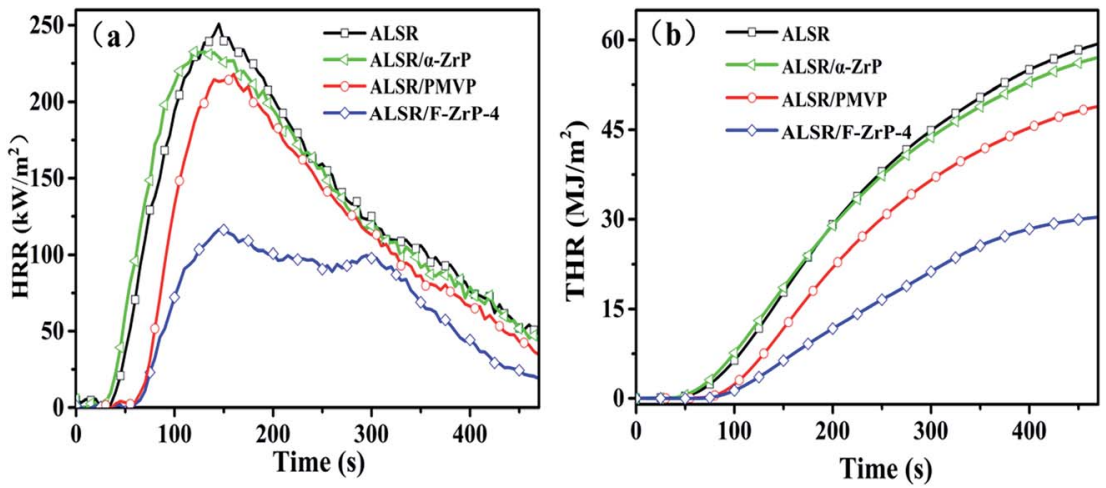

Fig. 5 HRR (a) and THR (b) curves of ALSR ALSR/PMVP, ALSR/ $\alpha-Z r P$ and ALSR/F-ZrP-4. 

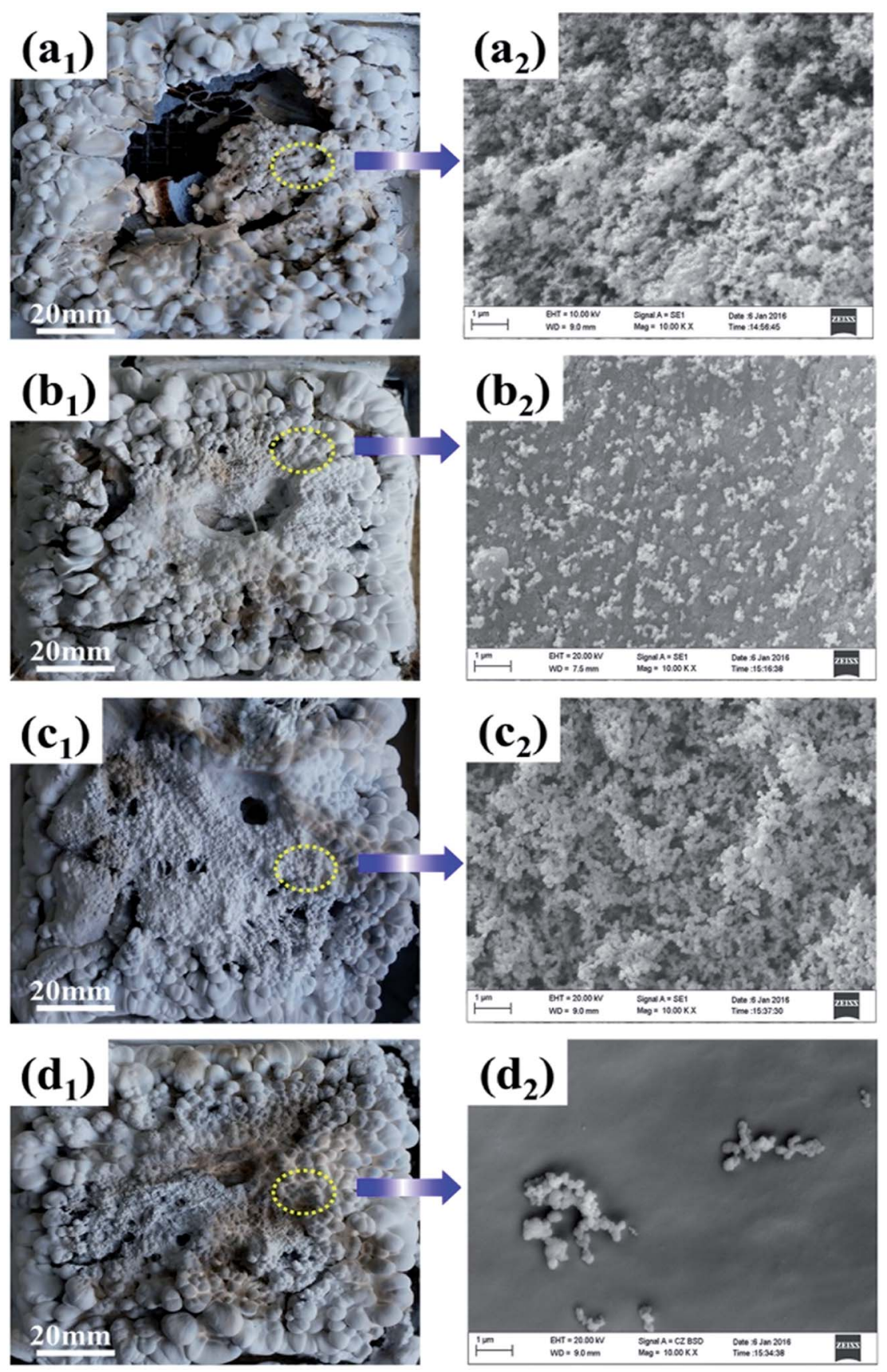

Fig. 6 Digital photographs (1) and SEM images (2) of residual chars of ALSR (a), ALSR/ $\alpha$-ZrP (b), ALSR/PMVP (c) and ALSR/F-ZrP-4 (d).

provide enough silicone chains for the subsequent selfcrosslinking reactions. On the other hand, PMVP improved the dispersion of ZrP nanosheets in ALSR, and the good dispersion of F-ZrP significantly enhanced the catalytic efficiency of ZrP to promote silicone chains self-crosslinking, resulting in the formation of the compact ceramic layer.

\subsection{TG-IR analysis}

Fig. S1 $\uparrow$ shows the 3D TG-IR spectra of the pyrolysis gases in the thermal degradation of ALSR (a) and ALSR F-ZrP-4 (b) under air atmosphere, and (c) the FTIR spectra of total volatile products for ALSR and ALSR/F-ZrP-4. For ALSR and ALSR/F-ZrP-4, four main small molecular gaseous species could be identified by their characteristic absorbance: cyclic oligomers $\left(2966 \mathrm{~cm}^{-1}\right.$, $1264 \mathrm{~cm}^{-1}, 1074 \mathrm{~cm}^{-1}, 1026 \mathrm{~cm}^{-1}$ and $849 \mathrm{~cm}^{-1}$ ), methane (3017 $\mathrm{cm}^{-1}$ and $\left.1304 \mathrm{~cm}^{-1}\right), \mathrm{CO}\left(2179 \mathrm{~cm}^{-1}\right.$ and $\left.2114 \mathrm{~cm}^{-1}\right)$ and $\mathrm{CO}_{2}\left(2359 \mathrm{~cm}^{-1}\right.$ and $\left.2314 \mathrm{~cm}^{-1}\right) .{ }^{32}$

Fig. 7 presents the evolution curves of the pyrolysis products, which are shown as the FTIR absorbance of pyrolysis products versus temperature, respectively. During the thermal degradation of ALSR, the release of $\mathrm{CH}_{4}$ could promote the crosslinking of the polysiloxane molecules, ${ }^{33}$ as shown in Scheme 1a. Therefore, the increase of $\mathrm{CH}_{4}$ facilitates the formation of tight 

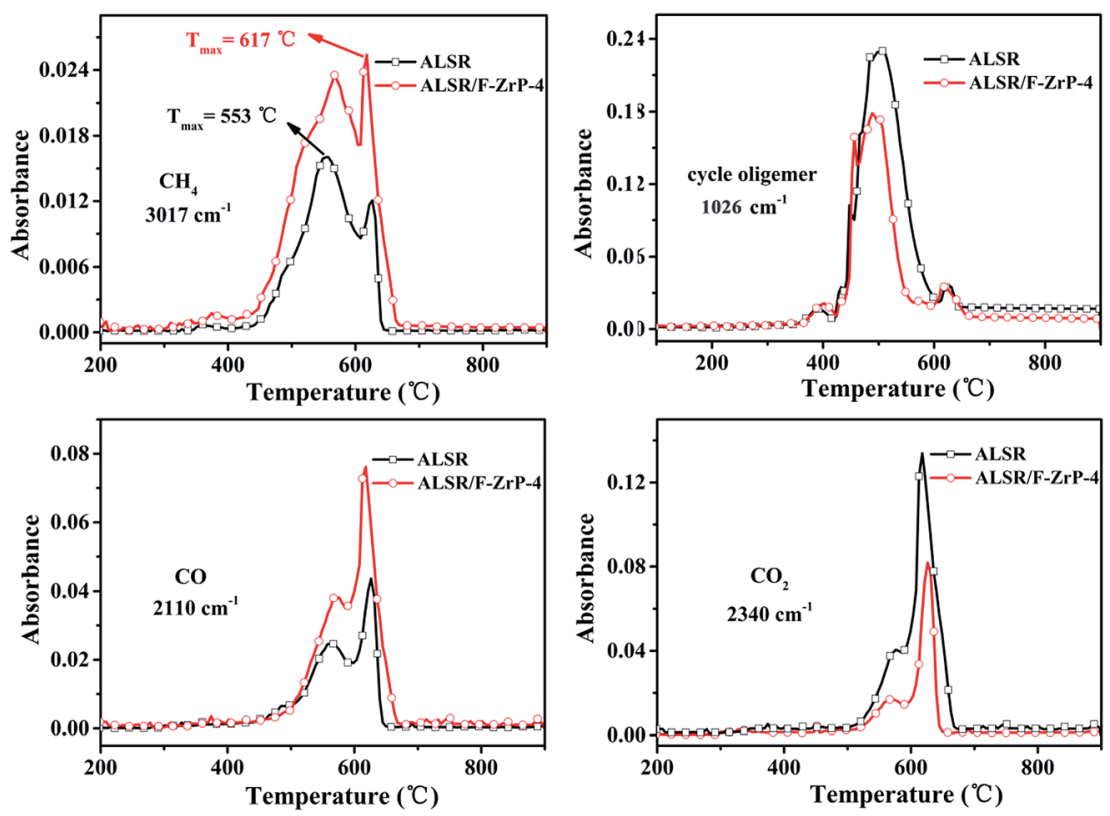

Fig. 7 FTIR absorbance versus temperature curves of pyrolysis products evolved from ALSR and ALSR/F-ZrP-4 under air atmosphere.

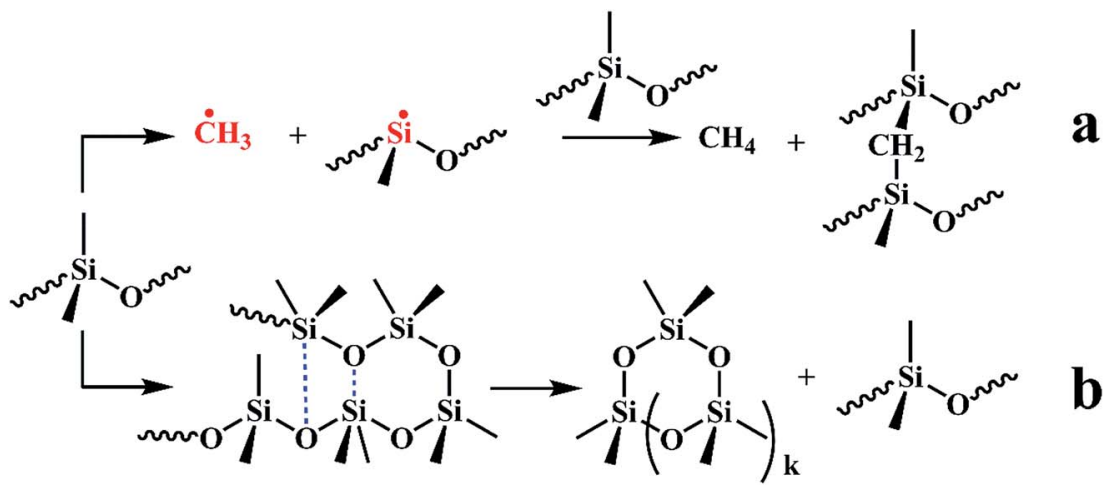

Scheme 1 The mechanism for the formation of methane (a) and cyclic oligomers (b).

silicone network. From Fig. 7, it was observed that the addition of F-ZrP significantly increased the evolution of $\mathrm{CH}_{4}$, indicating F-ZrP promoted silicone chains self-crosslinking to generate a compact ceramic layer.

According to G. Camino, the combustion of SR mainly takes place by the reaction between oxygen and cyclic oligomers to generate $\mathrm{CO}, \mathrm{CO}_{2}$ and $\mathrm{SiO}_{2} \cdot{ }^{34}$ In order to further understand the change of the pyrolysis products, the integrated areas of the absorbance peaks of the pyrolysis products are summarized in Table 5. As can be seen, after incorporating F-ZrP, the evolution of the main combustible gas (cyclic oligomers) decreased by $30.9 \%$, which was good in agreement with the improvements in the flame retardancy. However, it was worth noting that on the contrary of the decrease of cyclic oligomers, the release of CO of ALSR/F-ZrP-4 increased by 76.8\%, compared with ALSR. This strange phenomenon could be explained by that PMVP interrupted the thermo-oxidation process by the free-radical quenching effect to make cyclic oligomers incomplete oxidative degradation. Fig. $\mathrm{S} 2 \dagger$ shows FTIR absorbance $v s$. temperature curves of pyrolysis products of ALSR and ALSR/FZrP-4 in the nitrogen. As can be seen, there were only two kinds of pyrolysis products $\left(\mathrm{CH}_{4}\right.$ and cyclic oligomers) during thermal degradation of ALSR in the nitrogen. Compared to ALSR, the evolution of $\mathrm{CH}_{4}$ of ALSR/F-ZrP-4 increased, indicating that F-ZrP promoted silicone chains self-crosslinking to generate a compact ceramic layer, and the evolution of cyclic oligomers of ALSR/F-ZrP-4 significantly decreased. The decrease

Table 5 The integrated areas of the absorbance peaks of pyrolysis products evolved from ALSR and ALSR/F-ZrP-4

\begin{tabular}{llll}
\hline & \multicolumn{2}{l}{ Integrated area } & \\
\cline { 2 - 4 } Sample & Cyclic oligomers & $\mathrm{CO}$ & $\mathrm{CO}_{2}$ \\
\hline ALSR & 29.38 & 3.53 & 8.94 \\
ALSR/F-ZrP-4 & 20.31 & 6.24 & 3.88
\end{tabular}



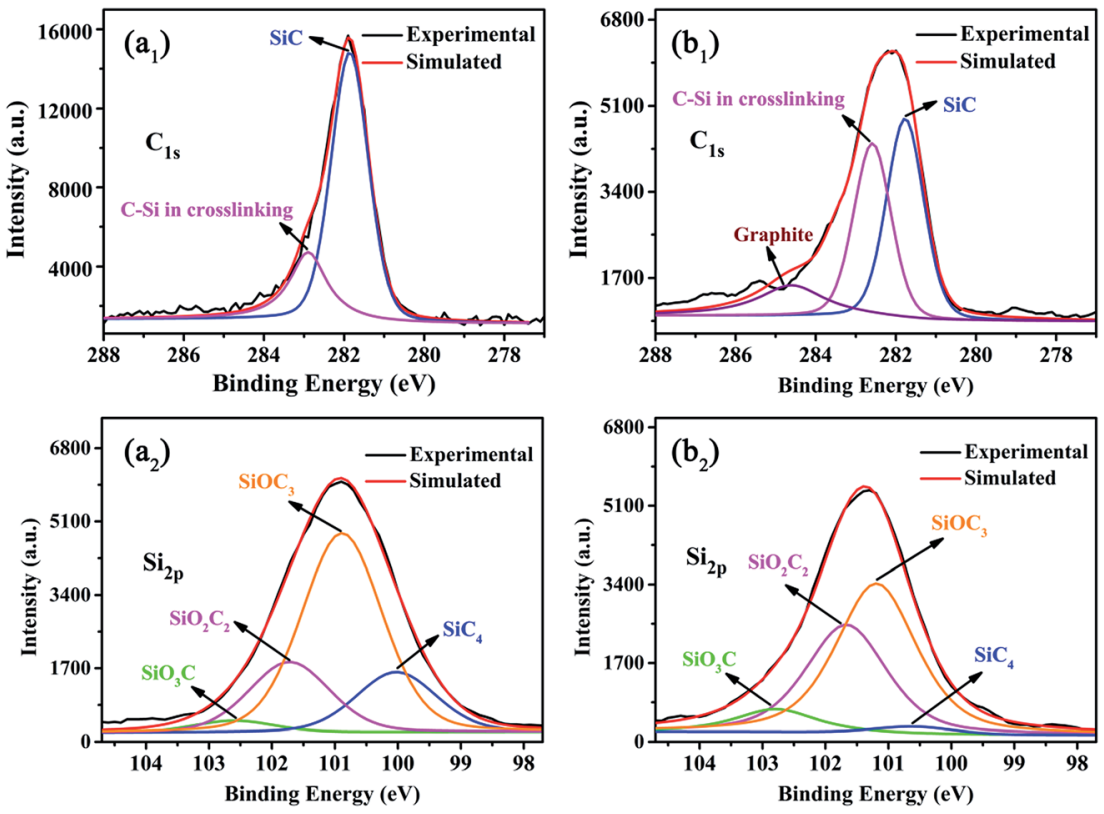

Fig. 8 XPS spectra of the residues for ALSR $\left(a_{1}, a_{2}\right)$ and ALSR/F-ZrP-4 $\left(b_{1}, b_{2}\right)$ after cone tests.

of cyclic oligomers would give rise to the improvement of flame retardancy of ALSR.

\subsection{XPS analysis}

In order to understand how F-ZrP acts in the condensed phase, the residues of ALSR and ALSR/F-ZrP-4 after cone tests are studied by XPS analysis, and the results are shown in Fig. 8. As seen from Fig. $8 \mathrm{a}_{1}$, the $\mathrm{C}_{1 \mathrm{~s}}$ peak of the residue of ALSR was split into two peaks. The peak at $281.8 \mathrm{eV}$ was assigned to $\mathrm{SiC}$ species. ${ }^{35}$ The peak at $282.7 \mathrm{eV}$ was attributed to $\mathrm{C}-\mathrm{Si}$ in the cross-linked network. ${ }^{36}$ For ALSR/F-ZrP-4, the content of the C$\mathrm{Si}$ structure in the cross-linked network greatly increased, compared with ALSR, indicating F-ZrP effectively promoted silicone chains self-crosslinking with the structure of $\mathrm{Si}-\mathrm{C}-\mathrm{Si}$. Furthermore, there was a new peak at $284.6 \mathrm{eV}$ in the $\mathrm{C}_{1 \mathrm{~s}}$ spectrum of the residue of ALSR/F-ZrP-4, which was assigned to $\mathrm{C}=\mathrm{C}$ in the graphite. ${ }^{37}$ As reported, the high content of graphitized carbons was beneficial to enhance the strength and thermostability of the residual chars. ${ }^{38}$

In Fig. $8 \mathrm{a}_{2}$ and $\mathrm{b}_{2}$, for ALSR and ALSR/F-ZrP-4, the $\mathrm{Si}_{2 \mathrm{p}}$ peaks of the residues were both split into 4 peaks. The peak at $100.2 \mathrm{eV}$ was assigned to the structure of $\mathrm{SiC}_{4}$, which might be $\mathrm{SiC}$ species. ${ }^{39}$ The peaks at $101.0 \mathrm{eV}, 101.6 \mathrm{eV}$ and $102.4 \mathrm{eV}$ were attributed to $\mathrm{C}_{3} \mathrm{SiO}, \mathrm{C}_{2} \mathrm{SiO}_{2}$ and $\mathrm{CSiO}_{3}$, respectively, which were all contributed to the formation of the cross-linked network

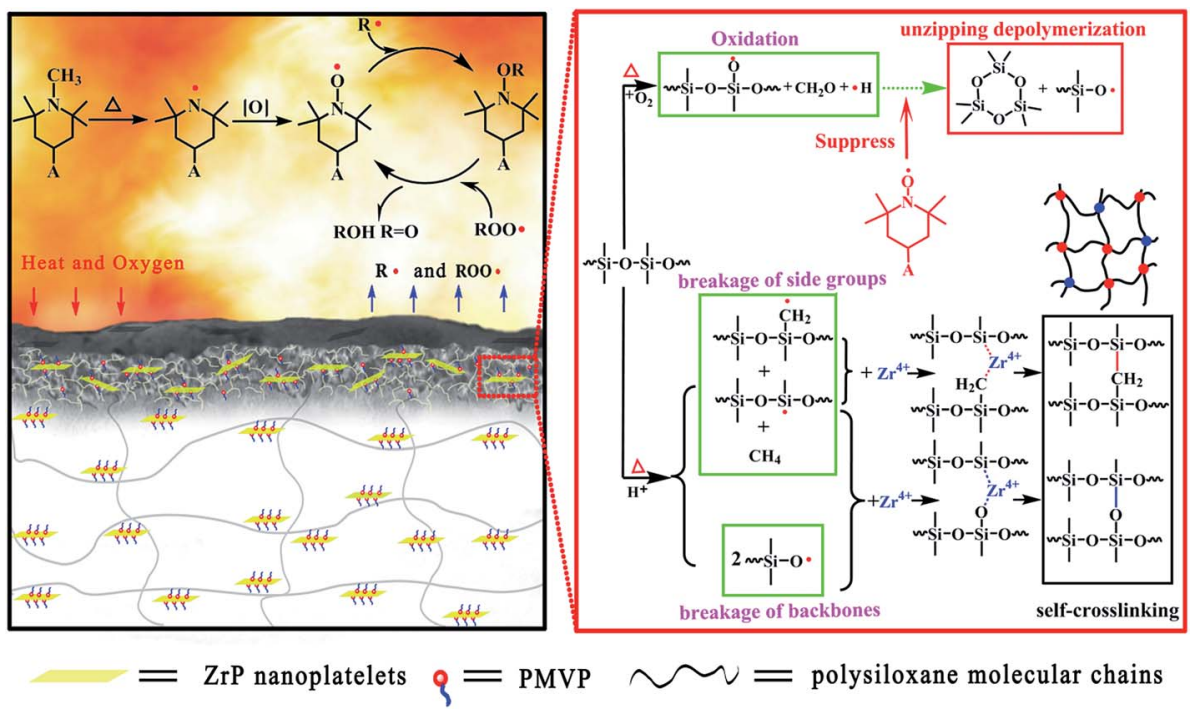

Fig. 9 Illustration for the flame-retardant mechanism of F-ZrP during the combustion of ALSR/F-ZrP. 
with the Si-O-Si structure. ${ }^{40}$ Compared with ALSR, the most obvious changes in the $\mathrm{Si}_{2 \mathrm{p}}$ peaks of the residue of $\mathrm{ALSR} / \mathrm{F}-\mathrm{ZrP}-4$ were the great increase of the $\mathrm{C}_{2} \mathrm{SiO}_{2}$ structure and the decrease of the $\mathrm{SiC}_{4}$ structure, which further confirmed that F-ZrP promoted silicone chains self-crosslinking with the bridged structure of $\mathrm{Si}-\mathrm{C}-\mathrm{Si}$ and suppressed the formation of SiC. Moreover, the structure of $\mathrm{CSiO}_{3}$ also increased, suggesting that F-ZrP also promoted the polysiloxane molecular chains selfcrosslinking with the structure of $\mathrm{Si}-\mathrm{O}-\mathrm{Si}$.

\subsection{Flame retardant mechanism of F-ZrP}

Based on the analysis mentioned above, it was evident that F-ZrP could efficiently enhance the flame retardancy of ALSR mainly due to the synergism of the catalyzing carbonization and free-radical quenching mechanism, as shown in Fig. 9. Owing to their good dispersion in ALSR as well as strong interfacial interactions between F-ZrP and the matrix, F-ZrP nanoplatelets acted as an excellent barrier to reduce the gas permeability, which not only delayed the degradation of the polysiloxane molecule segments, but also protected PMVP from the oxidation in advance. Once PMVP was oxidized to generate nitroxyl radicals, it suppressed the thermo-oxidative degradation of the polysiloxane molecules in the condensed phase and inhibited the chain reactions of the combustion in the gas phase by freeradical quenching effect.

When the temperature was further increased, F-ZrP thermally loosed $\mathrm{H}^{+}$, which attacked the polysiloxane molecules to form the macroradicals. ${ }^{18}$ Meanwhile, $\mathrm{Zr}^{4+}$ of F-ZrP captured macroradicals and lead to intermolecular cross-linking with the bridged structure of $\mathrm{Si}-\mathrm{C}-\mathrm{Si}$ and $\mathrm{Si}-\mathrm{O}-\mathrm{Si}$, resulting in the formation of the compact and thermostable ceramic layer which acted as an effective barrier against the heat transmission and oxygen diffusion. Furthermore, $\mathrm{Zr}^{4+}$ also promoted the formation of graphitic structure in the outer surface which enhanced the thermostability and strength of ceramic layer.

\section{Conclusions}

In this work, functionalized zirconium phosphate (F-ZrP) was prepared by the intercalation of PMVP into $\alpha$-ZrP, and F-ZrP could effectively enhance the flame retardancy of ALSR. When only 4.0 phr F-ZrP was added, the LOI value reached $31.0 \%$ and the vertical burning test (UL-94) passed the V-0 rating. Moreover, compared to ALSR, PHRR and THR values of ALSR/F-ZrP-4 decreased by $54.2 \%$ and $47.5 \%$, respectively. Such an efficient flame retardancy of FZrP was mainly attributed to the synergistic effect between the catalyzing carbonization and free-radical quenching effect. On the one hand, PMVP in the interlayer of F-ZrP was oxidized to generate nitroxyl radicals which retarded the thermal oxidative degradation of polysiloxane molecules in the condensed phase and quenched the active free-radicals in the gas phase; on the other hand, F-ZrP promoted silicone chains self-crosslinking and the formation of the graphitized carbons, leading to the formation of the compact and thermostable ceramic layers, which acted as an effective barrier against the heat transmission and oxygen diffusion.

\section{Conflicts of interest}

There are no conflicts to declare.

\section{Acknowledgements}

We greatly acknowledge the National Natural Science Foundation of China (51773064, 51403067, 51573052), the Natural Science Foundation of Guangdong Province (2017A030313303), the Special Funds for the Cultivation of Guangdong College Students' Scientific and Technological Innovation (pdjh2017a0028) for their financial supports.

\section{Notes and references}

1 H. Y. Li, S. Tao, Z. T. Su and J. P. Zheng, Compos. Sci. Technol., 2013, 76, 52-60.

2 Z. Sun, Q. Huang, Y. Z. Wang and Y. P. Wu, RSC Adv., 2017, 7, 38915-38922.

3 A. Beaugendre, S. Saidi, M. Casetta and M. Jimenez, $R S C$ Adv., 2017, 7, 40682-40694.

4 I. Butnaru, M. Bruma and S. Gaan, RSC Adv., 2017, 7, 5050850518.

5 H. S. Devarennes, R. Sonnier and F. Ganachaud, Polym. Degrad. Stab., 2009, 94, 465-495.

6 H. J. Sue, K. T. Gam, N. Bestaoui and A. Clearfield, Chem. Mater., 2004, 16, 242-249.

7 L. Tong, F. Qiu, T. J. Zeng, T. Sun and Y. Yang, RSC Adv., 2017, 7, 47999-48018.

8 A. Okada and A. Usuki, Macromol. Mater. Eng., 2006, 291, 1449-1476.

9 N. I. N. Ismail, A. Ansarifar and M. Song, Polym. Eng. Sci., 2013, 53, 2603-2614.

10 B. Pradhan and S. K. Srivastava, Composites, Part A, 2014, 56, 290-299.

11 J. Alongi and A. Frache, Polym. Degrad. Stab., 2010, 95, 19281933.

12 X. Z. Wang, D. Zhao, A. Diaz and A. Clearfield, Chem. Commun., 2013, 52, 4832-4835.

13 B. M. Mosby, A. Diaz and A. Clearfield, ACS Appl. Mater. Interfaces, 2014, 6, 585-592.

14 C. Zhu, C. Deng, J. Y. Cao and Y. Z. Wang, Polym. Degrad. Stab., 2015, 121, 42-503.

15 D. D. Yang, Y. Hu, L. Song and Y. B. Cai, Polym. Degrad. Stab., 2008, 93, 2014-2018.

16 Y. J. Zhou, Y. Z. Meng and L. Y. Sun, ACS Appl. Mater. Interfaces, 2014, 6, 7417-7425.

17 J. Alongi, G. Camino and G. Malucelli, J. Anal. Appl. Pyrolysis, 2014, 108, 212-221.

18 D. D. Yang, Y. Hu, L. Song and H. P. Xu, J. Therm. Anal. Calorim., 2015, 119, 619-624.

19 K. Cao, S. L. Wu and L. Shao, Ind. Eng. Chem. Res., 2013, 52, 309-317.

20 H. L. Xie, Y. J. Zhang and X. R. Zeng, Polym. Degrad. Stab., 2015, 118, 167-177.

21 L. Y. Sun, W. J. Boo and A. Clearfield, New J. Chem., 2007, 31, 39-43. 
22 J. W. Gu, X. D. Meng and J. Kong, Composites, Part A, 2017, 92, 27-32.

23 F. Carosio, J. Alongi and G. Malucelli, J. Mater. Chem., 2011, 21, 10370-10376.

24 E. N. Kalali, S. D. Juan and D. Y. Wang, J. Therm. Anal. Calorim., 2015, 121, 619-626.

25 L. S. Brandao, L. C. Mendes and M. L. Dias, J. Appl. Polym. Sci., 2006, 102, 3868-3876.

26 F. Bauer and M. Willert-Porada, J. Membr. Sci., 2004, 233, 141-149.

27 H. L. Xie, X. J. Lai, H. Q. Li and X. R. Zeng, Polym. Degrad. Stab., 2016, 130, 68-77.

28 F. Bellezza, A. Cipiciani and M. E. Negozio, Langmuir, 2002, 18, 8737-8742.

29 S. S. Chen, X. Li, Y. Li and J. Q. Sun, ACS Nano, 2015, 9, 40704076.

30 F. Sun, T. Yu, C. Q. Hu and Y. Li, Compos. Sci. Technol., 2016, 136, 76-84.
31 F. P. Lou, L. H. Cheng and W. H. Guo, RSC Adv., 2017, 7, 38805-38811.

32 W. Z. Fang, X. R. Zeng, X. J. Lai and Y. J. Zhang, Thermochim. Acta, 2015, 605, 28-36.

33 G. Camino, S. M. Lomakin and M. Lazzari, Polymer, 2002, 43, 2011-2015.

34 G. Camino, S. M. Lomakin and M. Lazzari, Polymer, 2001, 42, 2395-2402.

35 P. Lv, X. Tang and W. Wei, RSC Adv., 2017, 7, 47116-47124. 36 A. Abdolmaleki, S. Mallakpour and S. Borandeh, Polym. Compos., 2016, 37, 1924-1935.

37 J. Alongi, G. Camino and G. Malucelli, Carbohydr. Polym., 2013, 92, 1327-1334.

38 S. B. Zhang and H. J. Wang, J. Therm. Anal. Calorim., 2011, 103, 711-716.

39 H. T. Chiua, T. Sukachonmakul and K. Wattanakul, Appl. Surf. Sci., 2014, 292, 928-936.

40 R. J. E. Corriu, D. Leclercq and A. Vioux, J. Sol-Gel Sci. Technol., 1997, 327-330. 